in males in the I.Q. range $30-55$. While this is perhaps an overestimate it emphasizes the importance of the condition and of a determined attempt to identify biochemical or other diagnostic tests by which this form may be identified in the absence of a family history pointing to X-linkage. It is also clearly important to look for evidence of $\mathrm{X}$-linkage when counselling parents of a boy in the I.Q. range of 30-55 on the risks of recurrence.

\footnotetext{
1 Renpenning, H., et al., Canadian Medical Association fournal, 1962, 87, 954.

${ }^{2}$ Dunn, H. G., Renpenning, H., and Gerrard, J. W., American fournal of Mental Deficiency, 1963, 67, 827.

${ }^{3}$ Martin, J. P., and Bell, J., Fournal of Neurology and Psychiatry, 1943, 6,

154.
4 Lehrke, R. G., X-linked Mental Retardation and Verbal Disability. Birth Defects Original Article Series, 1974, vol. X, no. 1

5 Davison, B. C. C., British fournal of Psychiatry, Special Publication, no. 8, 1973.

- Turner, G., and Turner, B., Fournal of Medical Genetics, 1974, 11, 109.

Turner, G., Turner, B., and Collins, E., Developmental Medicine and Child Neurology, 1971, 13, 71 .
}

\section{Better Medical Writing}

Daunting as the prospect may be of writing one's first medical article, there are no grounds for panic. Firstly, any article should answer Bradford Hill's basic questions ${ }^{1}$ : why did you start, what did you do, what did you find, and what does it mean?-to which perhaps another might be added: and what are you going to do about it ? Secondly, however well justified Medawar's ${ }^{2}$ criticisms of the artificiality of the scientific paper, most writers are helped by the formal Imrad structureIntroduction; Material, or Patients, and Methods; Results; and Discussion (together with an Abstract or Summary)-and it is a mistake to mix comments with descriptions of methods or results. Thirdly, follow the general rules for writing good English: choose the correct word; prefer the simple to the pompous word; prefer the concrete to the abstract; avoid circumlocutions; use short and Saxon words rather than long and Romance-derived ones; and write with nouns and verbs rather than adjectives and adverbs.

Even with all these ground rules, however, the potential author will still have many questions: how do I choose a journal, present my data, correct the proofs ? There is no shortage of books to answer these for him,,$^{3-6}$ but the latest to appear is perhaps the most comprehensive and also represents a new approach to an old problem. Writing Scientific Papers in English, ${ }^{7}$ by Maeve O'Connor and Peter Woodford includes chapters on planning, revising, and typing an article, as well as responding to the editor; and among the appendices there are guides to abbreviations and symbols and expressions to avoid. The European Life Science Editors Group, who joined with the Ciba Foundation in sponsoring the book, hope that it will be a core manual of science writing in English. Two sets of supplements are planned, one giving style details relevant to each of the main life sciences, the other providing specific guidelines for special language groups-for, as any editor will testify, the mistakes made by an author from Helsinki are likely to be quite different from those made by one from Baghdad.

Unlike many books on writing, moreover, Writing Scientific Papers in English practises what it preaches, being a model of clarity. If its sales are as wide as they deserve perhaps the millennium may be nearer when all journals will use the same basic style conventions (this week the B.M.F. has made a modest start, for soon all our references will be given in the numbered system, rather than a mixture of the Harvard and the numbered styles).

The book may be faulted only on one minor point: it fails to emphasize the value of the local journal. Too many authors regard their university or national journal as a third best-the last refuge for an article after it has been the rounds of the international general and special journals. Yet local journals flourish all over the world, reporting work and data of practical importance-not necessarily original for the world but almost certainly for that community. Authors often say that these journals have too low a standard or small a circulation for them to want to use these, but the remedy is in their own hands: by submitting their best work to them they can break any vicious circle in a short time.

Nevertheless, in any discipline, competence is finally obtained by practice under supervision. Traditionally the head of a department should go over the articles written by his juniors, correcting scientific errors and improving style and presentation. Yet today few supervisors have enough time or even experience to do this, and a mere glance at the 50 or so original articles the B.M.F. receives every week would show how poorly the system is working. Editors in the U.S.A. have tried several ways to raise the numbers of clear and coherent scientific articles. Professional writers have been introduced into research teams or attached to large hospitals; journals have employed "rewrite specialists"; and another approach has been courses in medical writing - and modest attempts in this direction have been made elsewhere ${ }^{8}$ Certainly it would be wrong to add anything to the already overloaded undergraduate curriculum, but there is much to be said for teaching postgraduates the elements of clear writing. How this should be done will vary with individual needs: one specialty may need only two hours of discussion, another a short course of practical exercises as well. This autumn the B.M.F. plans to hold a one-day seminar on "Speaking and Writing in Medicine," which it is intended will include contributions on clear writing, the principles of refereeing, and drafting an M.D. thesis as well as tuition in small groups on individual problems. Further details will be given later.

\footnotetext{
1 Bradford Hill, A., British Medical fournal, 1965, 2, 870.

2 Medawar, Sir P., Art of the Soluble. London, Methuen, 1967.

Hawkins, C. F., Speaking and Writing in Medicine. Springfield, Ill., Charles C. Thomas, 1967

4 Thorne, C., Better Medical Writing. London, Pitman Medical, 1970.

Barabas, A., and Calnan, J., Writing Medical Papers: a Practical Guide. London, Heinemann Medical Books, 1973.

${ }^{B}$ Council of Biology Editors Style Manual. Washington, D.C., American Institute of Biological Sciences, 1972.

7 O'Connor, Maeve, and Woodford, F. P., Writing Scientific Papers in English. Associated Scientific Publishers, Amsterdam, 1975.

${ }^{8}$ Collan, Y., Lock, S. P., and Whimster, W. F., British Medical fournal, $1974,1,627$.
}

\section{Short Reports}

This week we are publishing a new type of original medical articles. Called Short Reports, these will replace the Medical Memoranda, and be strictly limited to 600 words, up to five references, and one table or figure-and, like our Original Articles, they will be subject to assessment by an outside expert referee. Subjects such as adverse effects of a drug or single case reports will almost always be suitable for this format; occasionally they will not and may be considered as "traditional" Original Articles in the usual way. The first Short Reports appear at p. 68. 